\title{
Utility of diffusion-weighted magnetic resonance imaging in diagnosing hepatocellular carcinoma in cirrhotic liver
}

\author{
Diffüzyon ağırlıklı magnetik rezonans görüntülemenin, \\ sirotik karaciğerde hepatosellüler kanser tanısında yararı
}

\author{
Ahmet ASLAN ${ }^{1}$, Ibrahim INAN ${ }^{2}$, Vildan KARAGÖZ ${ }^{2}$, Mine ASLAN ${ }^{1}$, Murat ACAR ${ }^{2,3}$
}

\section{ABSTRACT}

We aimed to introduce the utility of diffusion-weighted images (DWI) in differentiating hepatocellular carcinoma (HCC) from dysplastic nodules (DN) in cirrhotic liver. DWI studies of the patients who had cirrhosis and HCC or cirrhosis and DN were evaluated retrospectively. Signal intensities of the lesions were classified as hyper-, iso- or hypointense on DWI. Apparent diffusion coefficient $(A D C)$ and $A D C$ ratios (the ratio between lesion $A D C$, and $A D C$ of the surrounding liver parenchyma) was obtained, and mean values were compared. Statistical significance was set at $p<0.05$. Ninety-five lesions were diagnosed with HCC and forty-four lesions with DN from a total of 87 patients. The hyperintensity on DWI, mean $A D C$, and $A D C$ ratio of HCCs were statistically significant ( $p<0.001$ for all parameters). An ADC value of $\leq 1.316 \times 10^{-3} \mathrm{~mm}^{2} / \mathrm{s}$ and an $A D C$ ratio of $\leq 0.94$ obtained by ROC curve analysis, were found to be the best cut-off values. DWI alone has a limited capability to detect HCC, but it can be used for imaging cirrhotic liver to supply ancillary findings in addition to dynamic contrast-enhanced MRI in diagnosing HCC.

Keywords: Cirrhosis, hepatocellular carcinoma, dysplastic nodule, magnetic resonance imaging, diffusion weighted imaging, diagnostic imaging
Öz

Bu çalışmada, sirotik karaciğerde hepatosellüler kanseri (HSK), displastik nodüllerden (DN) ayırımında diffüzyon ağırıklı görüntülerin (DAG) yararını ortaya koymayı amaçladık. Siroz ve hepatosellüler kanser veya siroz ve displastik nodülü olan hastaların $D A G$ 'ları geriye dönük olarak değerlendirildi. DAG'da lezyonların sinyal intensiteleri hiper, izo veya hipointens olarak sınıflandırıldı. Apparent diffusion coefficient $(A D C)$ ve $A D C$ oranları (lezyon $A D C$ 'sinin lezyonu çevreleyen karaciğer parankimi $A D C^{\prime}$ 'sine oranı) karşılaştırıldı. istatistiksel anlamlılı $p<0,05$ olarak kabul edildi. Seksen yedi hastadan, 95 HSK tanılı lezyon ve 44 DN tanılı lezyon elde edildi. DAG'da hiperintensite, ortalama $A D C$ ve $A D C$ oranı istatistiksel olarak anlamlı bulundu $(p<0,001$ tüm parametreler için). ROC analizi ile ADC değeri olarak $1.316 \times 10^{-3} \mathrm{~mm}^{2} / \mathrm{s}$ veya altı ve $A D C$ oranı olarak 0,94 veya altı, en iyi kestirim değeri olarak hesaplandı. DAG tek başına HSK tespit etmede kısıtlı kabiliyete sahiptir. Ancak dinamik kontrastlı MRG'ye ek olarak, sirotik karaciğerde HSK tanısında yardımcı bulgular sağlayabilmek için kullanılabilir.

Anahtar kelimeler: Siroz, hepatosellüler kanser, displastik nodül, magnetik rezonans görüntüleme, difüzyon ağırlıklı görüntüleme, tanısal görüntüleme

\section{INTRODUCTION}

Nodules in cirrhosis can present as regenerative, siderotic or dysplastic nodules, and lead to hepatocellular carcinoma $(\mathrm{HCC})^{1}$. Early detection and differentiation of HCC are important for appropriate and curative treatment methods ${ }^{2,3}$. Dynamic contrast-enhanced magnetic resonance imaging (DCE-MRI) is now widely used as a reference test for the non-invasive diagnosis of HCC in cirrhotic liver without any need for biopsy according to the American Association for the
Study of Liver Diseases (AASLD), the European Association for the Study of the Liver (EASL) guidelines, and Liver Imaging Reporting and Data System (LIRADS) ${ }^{2-5}$. However, the long time required for image acquisition in MRI, and the high cost of contrast materials (gadolinium-based agents) and their side effects, especially in patients with renal insufficiency, can limit the usage of these imaging modalities. Therefore, additional imaging findings are needed to be defined in such cases.

Received: 18.06.2016

Accepted: 08.08.2016

${ }^{1}$ Department of Radiology, Ümraniye Training and Research Hospital, Istanbul, Turkey

${ }^{2}$ Department of Radiology, Göztepe Training and Research Hospital, Medical School of Istanbul Medeniyet University, Istanbul

${ }^{3}$ Department of Radiology, King Hamad University Hospital. Bahrain

Yazışma adresi: Ahmet Aslan, Department of Radiology, Ümraniye Training and Research Hospital, Istanbul

e-mail: aslahmet@gmail.com 
Diffusion-weighted imaging (DWI) obtained within a duration of a single breath-hold time which does not require contrast material, has gained attention and can provide qualitative (signal intensity) and quantitative (ADC-apparent diffusion coefficient) data ${ }^{3-7}$. This technique now is widely used in other parts of the body for displaying fibrosis, ischemia, and malignancy. There are encouraging studies regarding DWI for detecting focal liver masses in the medical literature, but there is limited data about the usefulness of DWI in differentiating HCC from dysplastic nodule (DN) in cirrhosis ${ }^{8}$. This paper aimed to introduce the utility of DWI for the differentiation of HCC from DN diagnosed by typical imaging findings in cirrhosis.

\section{MATERIAL and METHODS}

The retrospective design of the study was approved by the Institutional Ethics Committee and the requirement for informed written consent was waived.

\section{Patients}

The patients for whom abdominal MRI reports included the keywords of cirrhosis and HCC or cirrhosis and DN between August 2011 and March 2015 were searched in the radiology information system (RIS) and 201 patients were found. Patients who had received chemotherapy or transarterial chemoembolization before the abdominal DCE-MRI and who had diffuse HCC or nodules with atypical DCE-MRI findings for HCC were excluded from the study. Also, patients without histopathological confirmation of cirrhosis who had DCE-MRI findings for HCC but nodules smaller than $2 \mathrm{~cm}$, and patients who had MR images with intense motion artifacts were excluded from the study because of difficulties in measurements on ADC maps. Two patients with intense motion artifacts on MR images, 62 patients for whom we did not detect DN or HCC, and 5 patients with HCC nodules smaller than $2 \mathrm{~cm}, 2$ patients with diffuse HCC, 28 patients who had atypical DCE-MRI findings, 3 patients without DCE-MRI, 2 patients who received radiofrequency ablation therapy before the DCE-MRI and 10 patients without DWI were excluded from the study.
If a single patient had several studies, the last convenient MRI study with DCE-MRI and DWI was used for collecting data. Diagnosis of HCC and DN was made according to the presence of characteristic DCE-MRI findings. Finally, 87 patients with a diagnosis of HCC and/or DN were enrolled in the study.

\section{Magnetic Resonance Imaging Protocol}

DCE-MRI was performed with two 1.5-T superconducting magnetic resonance imaging systems (Signa HDxt 1.5 T-Optima Edition and Optima MR450w, General Electric Healthcare, Milwaukee, WI, USA) with 16 and 32 channel phased-array body coils, respectively. Breath-hold T1- weighted and T2- weighted SSFSE, fat suppressed T2- weighted SSFSE, T1- weighted in-phase and opposed-phase images, 3D FIESTA images and DCE 3D imaging with breath-hold fast spoiled gradient echo -LAVA- (for arterial phase at 20-35 sec, for portal venous phase at $60-75 \mathrm{sec}$ and late images at $180-240 \mathrm{sec}$ ) were performed in axial planes. DCE-MRI was performed after the administration of $0.1 \mathrm{mmol} / \mathrm{kg}(0.5 \mathrm{mmol} / \mathrm{mL})$ of extracellular gadolinium based contrast agent (Gd-DOTA, DOTAREM, Guerbet, Roissy CdG Cedex, France) at a rate of $2 \mathrm{~mL} / \mathrm{sec}$ with a $20 \mathrm{cc}$ saline flush. DWI was performed before contrast medium administration using a breath-hold single shot echo-planar spin echo sequence on the axial plane and tridirectional diffusion gradients $(T R / T E=10500 / 88.4 \mathrm{~ms}$, slice thickness $=5 \mathrm{~mm}$, matrix $=128 \times 128, \mathrm{FOV}=420 \times 420$ $\mathrm{mm}$, slice gap $=0.5 \mathrm{~mm}$ ). The gradient factors used (b values) were 0 and $800 \mathrm{~s} / \mathrm{mm}^{2}$. ADC maps were created from the DWI using Functool software on a workstation (ver. 5x2.1.06 GE, Healthcare, Waukesha, Wisconsin, USA).

\section{Diagnostic Criteria}

We used LI-RADS imaging criteria, AASLD, and EASL practice guidelines to diagnose $\mathrm{HCC}$ and $\mathrm{DN}^{2-5}$. Liver nodules that displayed a marked uptake of contrast agent on DCE-MRI in the arterial phase and displayed wash-out in the later phases were evaluated for the presence $\mathrm{HCC}^{2-5,10}$. If the liver nodule size was 
between 10-19 $\mathrm{mm}$ and displayed peripheral thin capsular enhancement in portal venous or delayed phases, and/or increased in size in a six-month interval follow-up imaging, then it was accepted as HCC (LI-RADS 5). A nodule larger than $20 \mathrm{~mm}$ which displayed wash-out of the contrast agent or capsular enhancement or increased in size was also accepted as HCC. Regardless of its DCE-MRI findings; if a cirrhotic nodule invaded the portal venous and/or hepatic venous channels, it was diagnosed as HCC 5,10,11 (Figure 1). A cirrhotic nodule was accepted as DN if it was iso- or hyperintense on T1- weighted images, iso- or hypointense on T2- weighted images, iso- or hypointense in the arterial phase, and isointense relative to the adjacent liver parenchyma ${ }^{1-5,9}$. Also, previous DCE-MRI of the patients with DN were evaluated and if the lesions were stable at two years' follow-up, then they were accepted as $\mathrm{DN}^{12}$. Visual inspection was used to determine arterial enhancement and washout in portal venous and delayed phases and subtraction images were used to confirm arterial phase enhancement when the lesion was hyperintense on T1- weighted images (Figure 2).

\section{Image Analysis}

One of the observers, who searched the RIS, collected the clinical, and demographic data of the patients enrolled in the study. MRI of the patients was evaluated for the presence of HCC or DN by the other two observers with 5, and 10-year experience in abdominal imaging, respectively. Both of the observers were blinded to patient identity and clinical findings. Finally, nodules detected in the liver were classified as HCC or DN if they met the diagnostic criteria set by the consensus of the two observers.

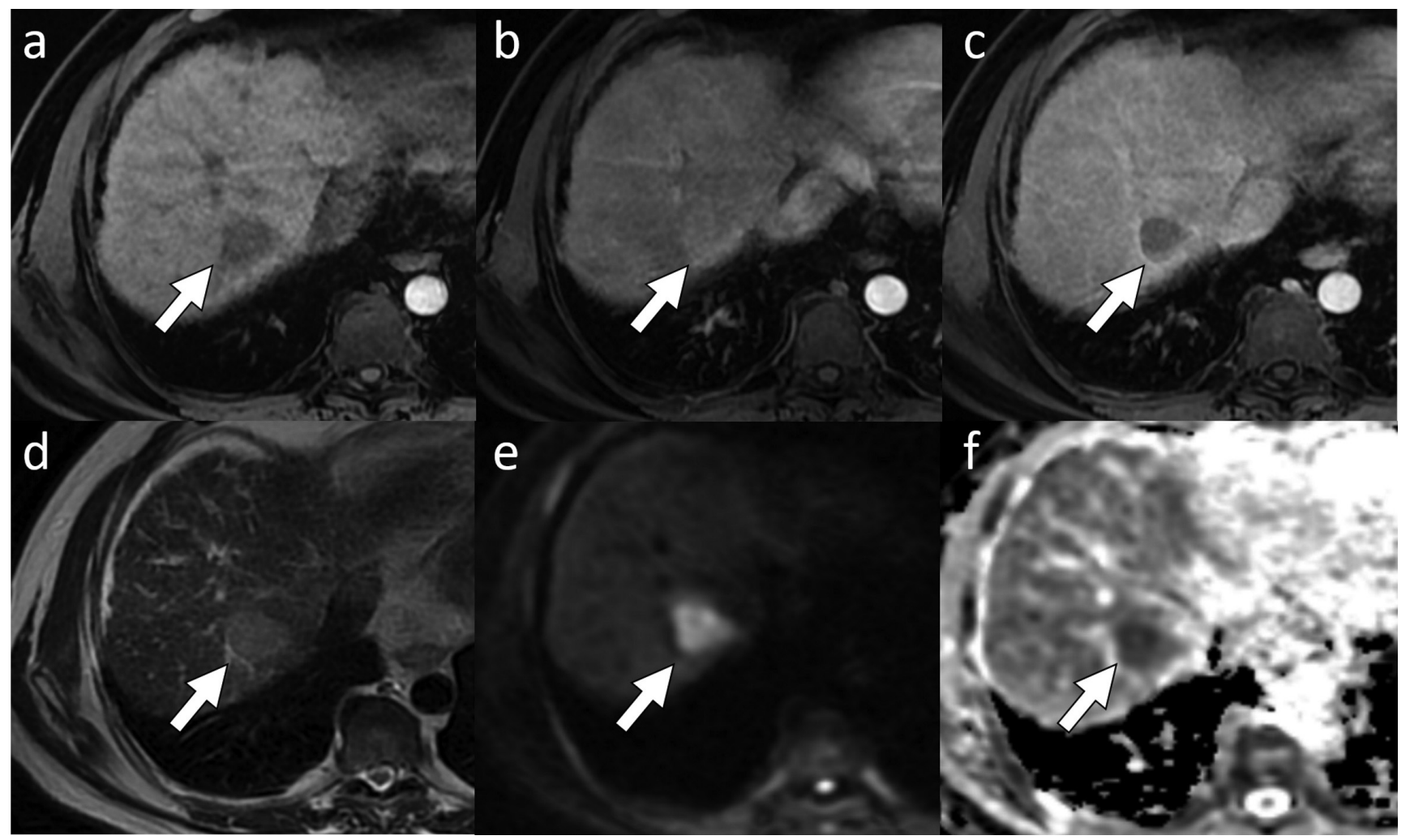

Figure 1a-f. Hepatocellular carcinoma in a 55-year-old male patient. Axial (a) fat-suppressed T1-weighted image shows a hypointense mass in segment 4a (white arrow). Axial (b) arterial phase image after contrast matter administration on T1-weighted image demonstrate early enhancement of the mass (white arrow). Axial (c) hepatic venous phase image on T1-weighted image shows contrast washout with thin capsular enhancement, typical for hepatocellular carcinoma (white arrow). The mass has a slightly high signal on axial (d) T2-weighted image (white arrow). Diffusion-weighted image $\left(b=800 \mathrm{~s} / \mathrm{mm}^{2}\right)$ (e) displays high signal intensity in the mass (white arrow). The mass seems hypointense on the apparent diffusion coefficient map (f) obtained with b values of 0 and $800 \mathrm{~s} / \mathrm{mm}^{2} \mathrm{due}$ to diffusion restriction (black arrow). 


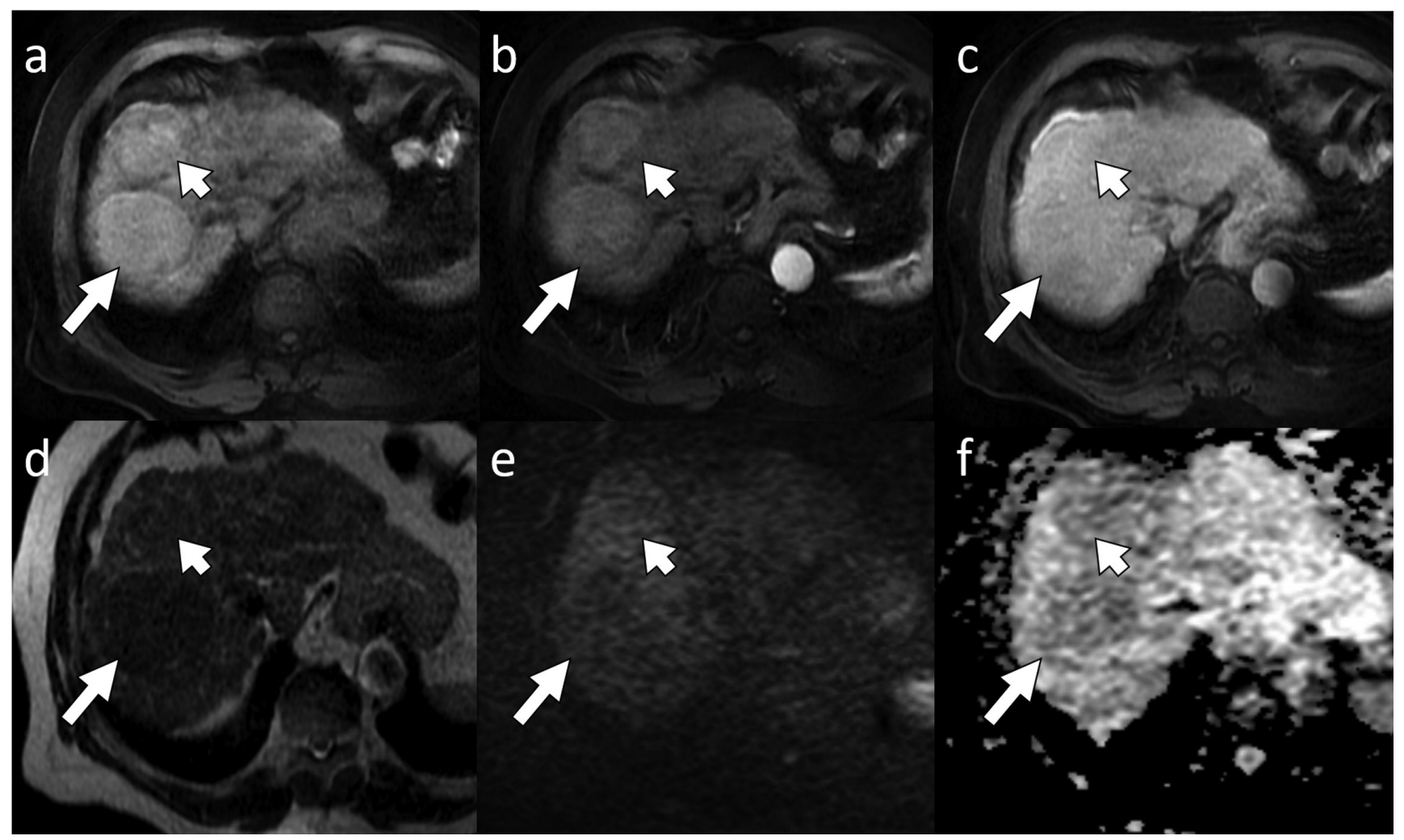

Figure 2. a-f. Dysplastic nodule in a 65-year-old female with chronic liver disease. Axial (a) fat-suppressed T1-weighted image without contrast matter administration shows round shaped hyperintense nodule in segment six (arrow). Note hyperintense gallbladder (arrowhead). No significant enhancement is demonstrated in the arterial phase image on axial (b) T1-weighted image after contrast matter injection (arrow). Subtraction images also confirmed this finding (not shown). On axial (c) portal phase image, the nodule is isointense and cannot be distinguished from hepatic parenchyma (arrow). Axial (d) T2-weighted image shows low signal intensity of the nodule (arrow). The nodule seems slightly hypointense on diffusion weighted image (e) compared to hepatic parenchyma and has a hypo-iso signal intensity on the apparent diffusion coefficient map (f) (arrow).

The maximum diameters $(\mathrm{mm})$ of the HCCs and DNs were measured on axial images as a reference in the sequences which lesions were clearly depicted. Intensities of HCCs and DNs were classified by visual inspection as iso-, hypo- or hyperintense relative to the surrounding liver parenchyma on DWI by the consensus of two observers. ADC values of the HCCs and DNs were obtained from the ADC maps using a round $\mathrm{ROI}$ of $1 \mathrm{~cm}$ diameter. $A D C$ measurements were taken from highly hypointense, and solid areas, avoiding necrotic or hemorrhagic parts in the lesion on the same workstation by one of the two observers. The mean value of at least three ROI measurements on lesions was used to obtain ADC values. The ADC value of the liver parenchyma surrounding the lesion was then measured to calculate the ADC ratio of the lesion to surrounding liver parenchyma with avoiding major portal and hepatic veins, rege- nerative or siderotic nodules, arteriovenous shunts and other focal liver masses (Figure 3). If there was a discrepancy on imaging findings, a final decision was reached by consensus of the observers.

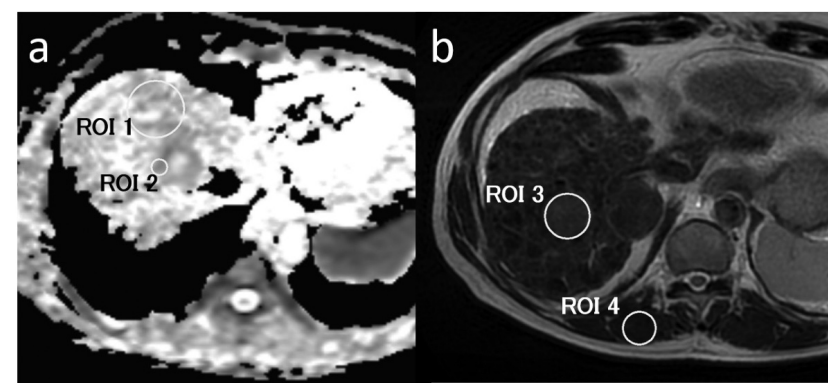

Figure 3a,b. ROI replacement. Transverse ADC mapping section of a patient with HCC shows the placement of ROI within hepatic parenchyma (ROI 1) and the solid component of the tumor (ROI 2). Care was taken not to sample from the necrotic component of the tumor. Transverse (b) T2-weighted image of a different patient with HCC and dysplastic nodules demonstrates the placement of ROI within the tumor (ROI 3) and 'paraspinal muscles (ROI 4). 


\section{Statistical Analysis}

Nodules were grouped as HCC or DN by DCE-MRI findings and the signal intensity on DWI and mean ADC and $A D C$ ratios were compared with each other. The Number Cruncher Statistical System (NCSS) 2007 and Power Analysis and Sample Size (PASS) 2008 Statistical Software (Utah, USA) were used to analyze the data. Numeric data were expressed as mean \pm SD or number (percentage), where suitable. The mean ADC and $A D C$ ratio were compared by Mann-Whitney $U$ test. Kruskal-Wallis test was used for comparing numeric data of three or more groups, and if there was a significant difference. Pearson's chi-square test, Yates Continuity Correction test, and Fisher-FreemanHalton test were used to compare qualitative data. The diagnostic performance of the $A D C$ and $A D C$ ratio was evaluated by performing the receiver operating characteristic (ROC) curve analysis, and the optimal cut-off points were determined by Youden's index, giving the same weight for sensitivity and specificity values. Odds ratio (OR) was used to predict the risk of malignancy in a nodule. Statistical significance was set at $p<0.05$ which was bidirectional.

\section{RESULTS}

From the RIS, 87 patients that met the inclusion criteria were enrolled in the study. Sixty-eight (78.1\%), patients were male and 19 (21.9\%)were female. Chronic liver disease was detected in all patients. Chronic liver disease was related to hepatitis B in 40 (45.9\%), hepatitis $C$ in 17 (19.5\%), and hepatitis $B$ and $C$ in 1 patient (1.1\%), and unknown in 29 (33.5\%) patients.

A total of 139 nodules (95 HCC nodules and $44 \mathrm{DN}$ ) detected in 87 patients were evaluated in the study. On follow-up MRI, 3 DNs turned into HCC and were classified as HCC in the statistical analysis.

The mean ages of the patients who had a diagnosis of HCC and DN were 65.2 \pm 8.3 (range 42 to 83 ) years and $62.9 \pm 7.2$ (range 51 to 73 ) years, respectively $(p=0.095)$. The mean diameter of HCC was $60.2 \pm 41.6$ (range 21-180) $\mathrm{mm}$ and of DNs was $22.4 \pm 9.8$ (range
$15-67) \mathrm{mm}(p<0.001)$. The signal intensity patterns of HCC and DNs on DWI are presented in Table 1. The sensitivity and specificity values, positive predictive value (PPV), negative predictive value (NPV) and accuracy of hyper-signal intensities on DWI were $88.4 \%$ (95\% Cl 79.8\% - 93.7\%), 100\% (95\% Cl 90\% - 100\%), $100 \%$ (95\% Cl 94.5\% - 100\%), 80\% (95\% Cl 66.6\% $89.1 \%)$ and $92.1 \%$, respectively.

Table 1. Signal intensity patterns of HCC and DN on DWI.

\begin{tabular}{lllll}
\hline \multirow{2}{*}{ Signal intensity } & \multicolumn{2}{c}{ Diagnosis } & \\
\cline { 2 - 3 } & \multicolumn{1}{c}{ HCC } & \multicolumn{1}{c}{ DN } & \multicolumn{1}{c}{$\mathbf{p}$} \\
\hline DWI & Hypointense & $1(1 \%)$ & $8(18.2 \%)$ & 0.001 \\
& Isointense & $10(10.6 \%)$ & $36(81.8 \%)$ & \\
& Hyperintense & $84(88.4 \%)$ & 0 & \\
\hline
\end{tabular}

${ }^{a}$ Fisher-Freeman-Halton Test

Abbreviations: HCC; hepatocellular carcinoma, DN; dysplastic nodule, DWI; diffusion weighted imaging.

The mean $A D C$ and $A D C$ ratio values of $H C C$ were $1.182 \pm 2.3 \times 10^{-3} \mathrm{~mm}^{2} / \mathrm{s}$ and $0.84 \pm 0.14$, DN were $1.432 \pm 2.31 \times 10^{-3} \mathrm{~mm}^{2} / \mathrm{s}$ and $1.00 \pm 0.13$ respectively ( $p<0.001$ for both parameters). A ROC analysis was performed for $A D C$ and $A D C$ ratio and a cut-off value of $\leq 1.316 \times 10^{-3} \mathrm{~mm}^{2} / \mathrm{s}$ for $A D C$, and $\leq 0.94$ for $A D C$ ratio had the best sensitivity, specificity, PPV and NPV for the differentiation of HCC from DNs (Table 2, Fi-

Table 2. Diagnostic utility of best cut-off values of ADC and ADC ratio in discriminating hepatocellular carcinoma in cirrhotic liver.

\begin{tabular}{llll}
\hline & & \multicolumn{1}{c}{$\begin{array}{c}\text { ADC } \\
(\%, 95 \% \mathrm{Cl})\end{array}$} & \multicolumn{1}{c}{$\begin{array}{c}\text { ADC ratio } \\
(\%, 95 \% \mathrm{CI})\end{array}$} \\
\hline ROC analysis & AUC & $0.806(0.730-0.869)$ & $0.825(0.75-0.884)$ \\
& $\mathrm{p}$ & 0.001 & 0.001 \\
Cut off value & & $\leq 1.316 \times 10^{-3} \mathrm{~mm}^{2} / \mathrm{s} \leq 0.94$ \\
Diagnostic scan & Sensitivity & $74.23(64.1-82.7)$ & $78.49(68.8-86.3)$ \\
& Specificity & $75(59.7-86.8)$ & $70.45(54.8-83.2)$ \\
& PPV & $74.8(64.9-82.7)$ & $72.6(63.1-80.5)$ \\
& NPV & $74.4(64.6-2.4)$ & $76.6(66.4-84.5)$ \\
& PLR & $2.97(1.8-5)$ & $2.66(1.7-4.2)$ \\
& NLR & $0.34(0.2-0.5)$ & $0.31(0.2-0.5)$ \\
Odds ratio & Accuracy & 74.6 & 74.5 \\
& & $8.88(4.67-16.85)$ & $8.96(4.69-17.13)$ \\
& p & $<0.001$ & $<0.001$
\end{tabular}

Abbreviations: ADC; apparent diffusion coefficient, $\mathrm{Cl}$; confidence interval, ROC; receiver operating curve, AUC; area under curve, PPV; positive predicting value, NPV; negative predicting value, PLR; positive likelihood ratio, NLR; negative likelihood ratio. 
gure 4). In order to provide a sensitivity of $99 \%$ and a specificity of $9.09 \%$, a value of $\leq 0.55 \mathrm{~mm}^{2} / \mathrm{s}$ can yield a specificity of $99 \%$ and a sensitivity of $1.08 \%$. An ADC ratio $\leq 1.77$ had a sensitivity of $99 \%$ and a specificity of $2.27 \%$, while a ratio of $\leq 0.515$ had a specificity of $99 \%$ and a sensitivity of $0 \%$.
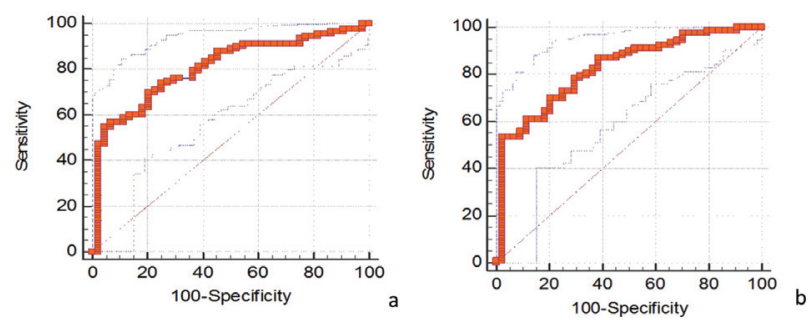

Figure 4. ROC curve for ADC (a), and ADC ratio (b).

\section{DISCUSSION}

Histopathological diagnosis of HCC is the gold standard method, but the location of the nodule, the presence of ascites, bleeding problems or seeding of the tumor through the needle track limit the use of invasive diagnostic methods ${ }^{13,14}$. For these reasons, characterizing a nodule in a patient with chronic liver disease by imaging methods has gained importance and is now used for the diagnosis of HCC without histopathological confirmation according to the AASLD EASL practice guidelines, and LI-RADS ${ }^{2-5}$. MRI is the preferred imaging method owing to lack of ionizing radiation, lower allergic reaction risk of the contrast material comparing to the $\mathrm{CT}$, and especially high accuracy in determining HCC in cirrhotic liver ${ }^{6-8}$. However, longevity of image acquisition which can be a problem for elderly or claustrophobic patients, the sensitivity of DCE-MRI to motion of the patient, intestinal peristaltism or cardiac activity, the high-cost contrast materials and their side effects can limit the utilization of DCE-MRI in cases with cirrhotic liver ${ }^{15}$. Therefore, additional MRI criteria have come forward which have provided higher rates of diagnosis without biopsy. In our study, we evaluated the use of DWI for differentiating HCC from DN and showed that DWI might have limited utility.

Several studies on liver MRI investigated the value of additional unenhanced MRI sequences for diagno- sing HCC. High signal intensity on T2-weighted images was used to evaluate liver masses before DCE-MRI was introduced, but the usefulness of signal intensity patterns on T2-weighted images is relatively low in the detection of HCC in cirrhotic liver ${ }^{13,15,16}$.

DWI, a fast and unenhanced MRI sequence, was recently proposed for evaluating and detecting HCC in cirrhotic livers ${ }^{3,5}$. In contrast to the surrounding liver parenchyma, the microstructure of the HCC is different because of the increased density of the cells, thickened cellular walls and arterial vascular supply. Thus, movement of water molecules is progressively restricted and results in a high signal intensity on DWI $7,17,18$. The sensitivity of hyperintensity on DWI for HCC varied between $67.5 \%$ and $95.2 \%$ according to recent studies ${ }^{3,5,12,19}$. In agreement with previously published reports, we obtained a sensitivity of 88.4 percent. In recent studies on DWI to evaluate hyperintensity of HCCs compared to the surrounding hepatic parenchyma, different $b$ values were used. Piana et al. found a sensitivity value of $72 \%$ or $82 \%$ depending on the reader and Xu et al. ${ }^{19}$ found a value of $67.5 \%$ with a $b$ factor of $500 \mathrm{~s} / \mathrm{mm}^{2}$, while Vandecaveye found a value of $95.2 \%$ with $a b$ factor of 600 $\mathrm{s} / \mathrm{mm}^{2}$ on $\mathrm{DWI}^{3,12}$. A consensus conference on $\mathrm{DWI}$ in cancer imaging stated that higher $b$ values are needed in high vascular tissues ${ }^{20,21}$. In the current study, we used a b factor of $800 \mathrm{~s} / \mathrm{mm}^{2}$ on DWI. Ichikawa et al. ${ }^{22}$ recommended using a b factor of $>400 \mathrm{~s} / \mathrm{mm}^{2}$ to achieve good and assessable DWI in abdominal MRI. Similarly, Vandecaveye et al. ${ }^{12}$ compared $b$ values of 0 $\mathrm{s} / \mathrm{mm}^{2}, 100 \mathrm{~s} / \mathrm{mm}^{2}, 600 \mathrm{~s} / \mathrm{mm}^{2}$ and $1000 \mathrm{~s} / \mathrm{mm}^{2}$, and stated that a b value of $600 \mathrm{~s} / \mathrm{mm}^{2}$ on DWI improved the detection of HCC, especially for tumors smaller than $2 \mathrm{~cm}$.

The signal intensity on DWI is affected by the T2 shine-through effect while the ADC value is not. Therefore, the exact value of restriction in diffusion can be assessed by ADC measurements of the lesions ${ }^{20}$. $A D C$ and $A D C$ ratio values of HCCs were significantly lower than DN in our study but lower than previously published reports ${ }^{3,19}$. We found an ADC value of $\leq 1.316 \times 10^{-3} \mathrm{~mm}^{2} / \mathrm{s}$ and an $A D C$ ratio of $\leq 0.94$ as the 
best cut-off points. ADC is a measure of signal loss related to the value of $a b$ factor. Thus, this difference may be related to the high value of $b$ factor we used $^{23}$. Also, we measured the ADC values from the darkest parts of the lesions, avoiding hemorrhage and necrosis, which may be related to our low ADC and $A D C$ ratios.

Recently, the American College of Radiology (ACR) proposed and updated a new reporting system for focal liver lesions detected in patients with chronic liver disease, called LI-RADS (Liver Imaging Reporting and Data System) and stated that mild and moderate hyperintensity on $\mathrm{T} 2$-weighted images and restricted diffusion are considered to be ancillary findings for $\mathrm{HCC}^{5,12,18}$. In the medical literature, there are limited studies comparing the efficacy of DWI in focal liver masses in cirrhotic liver. $A D C$ and $A D C$ ratios were significantly different in our study with a high odds ratio. However, as mentioned before, DWI parameters in cirrhotic liver with various degrees of fibrosis have not been well established. Also, iron, copper, fat, protein and glycogen content of HCC is variable and related to its grade of maturity, size, vascular supply, and the presence of necrosis, which could alter the signal intensity pattern on $\mathrm{DWl}^{8}$. We found significant differences between $A D C$ and $A D C$ ratios of HCC and DN in our study in which we used DCEMRI findings as a reference test, but our sensitivity and specificity values were moderately high, and this may restrict DWI's utility in clinical practice. We think that DWI should be used as a problem solver sequence with ancillary findings in monitoring cirrhotic liver, as stated in LI-RADS.

This study had some limitations. First, though the study had a was retrospective design, we evaluated the DCE-MRI and DWI of the patients in a prospective manner. We did not include the patients who had undergone any intervention before application of DCE-MRI and used the imaging criteria we decided upon to make a diagnosis. The presence of typical DCE-MRI findings was used as a reference test, and we did not have histopathological reports for all patients, which might have overestimated our findings.
This was primarily due to the design of our center, but we strictly obeyed AASLD and EASL practice guidelines, and the criteria for LI-RADS 1, 2, and 5 lesions, which are used to diagnose HCC or DN without a biopsy. We think that these imaging criteria are reliable to diagnose the HCC and DN. Also, contraindications for tru-cut needle biopsies in patients with cirrhosis (bleeding disorders, ascites, tumor seeding) and sampling errors kept us from obtaining tru-cut needle biopsies for HCC and DN. Additionally, ChildPugh classification could be assessed for the patients enrolled in the study. The degree of fibrosis might affect imaging characteristics of the nodules and liver parenchyma on DWI, and unknown homogeneity of the study group could lead to bias.

Qualitative and quantitative measurements on DWI have limited capacity to detect HCC in cirrhotic liver if used alone. However, DWI can be used as a problem solver imaging method with ancillary imaging findings for patients where contrast material cannot be administered or for claustrophobic patients where there is only a short time available for MRI.

\section{REFERENCES}

1. Parente DB, Perez RM, Eiras-Araujo A, et al. MR imaging of hypervascular lesions in the cirrhotic liver: a diagnostic dilemma. Radiographics 2012;32:767-787.

http://dx.doi.org/10.1148/rg.323115131

2. Bruix J, Sherman M. American Association for the Study of Liver Diseases. Management of hepatocellular carcinoma: An update. J Hepatol 2011;53:1020-1022. http://dx.doi.org/10.1002/hep.24199

3. Piana $G$, Trinquart $L$, Meskine $N$, et al. New MR imaging criteria with a diffusion-weighted sequence for the diagnosis of hepatocellular carcinoma in chronic liver diseases. J Hepatol 2011;55:126-132.

http://dx.doi.org/10.1016/j.jhep.2010.10.023

4. European Association for the Study of the Liver, European Organisation for Research and Treatment of Cancer. EASL-E ORTC clinical practice guidelines: Management of hepatocellular carcinoma. J Hepatol 2012;56:908-943. http://dx.doi.org/10.1016/j.jhep.2011.12.001

5. AJR LIRADS v2013.1 Available at: http://www.acr.org/qualitysafety/resources/LIRADS. Last accessed: May 1, 2015.

6. Lim KS. Diffusion-weighted MRI of hepatocellular carcinoma in cirrhosis. Clin Radiol 2014;69:1-10. http://dx.doi.org/10.1016/j.crad.2013.07.022

7. Guo L, Liang $\mathrm{C}, \mathrm{Yu} \mathrm{T}$, et al. $3 \mathrm{~T}$ MRI of hepatocellular carcinomas in patients with cirrhosis: does T2-weighted imaging provide added value? Clin Radiol 2012;67:319-328. http://dx.doi.org/10.1016/j.crad.2011.08.026 
8. Galea N, Cantisani V, Taouli B. Liver lesion detection and characterization: role of diffusion-weighted imaging. J Magn Reson Imaging 2013;37:1260-1276. http://dx.doi.org/10.1002/jmri.23947

9. Hussain SM, Reinhold C, Mitchell DG. Cirrhosis and lesion characterization at MR imaging. Radiographics 2009;29:16371652. http://dx.doi.org/10.1148/rg.296095508

10. Watanabe $A$, Ramalho $M$, AlObaidy $M$, et al. Magnetic resonance imaging of the cirrhotic liver: An update. World J Hepatol 2015;27:468-487. http://dx.doi.org/10.4254/wjh.v7.i3.468

11. Takayama T, Makuuchi M, Hirohashi S, et al. Malignant transformation of adenomatous hyperplasia to hepatocellular carcinoma. Lancet 1990;336:1150-1153. http://dx.doi.org/10.1016/0140-6736(90)92768-D

12. Vandecaveye V, De Keyzer F, Verslype C, et al. Diffusionweighted MRI provides additional value to conventional dynamic contrast-enhanced MRI for detection of hepatocellular carcinoma. Eur Radiol 2009;19:2456-2466. http://dx.doi.org/10.1007/s00330-009-1431-5

13. Rimola J, Forner A, Tremosini S, et al. Non-invasive diagnosis of hepatocellular carcinoma $\leq 2 \mathrm{~cm}$ in cirrhosis. Diagnostic accuracy assessing fat, capsule and signal intensity at dynamic MRI. J Hepatol 2012;56:1317-1323. http://dx.doi.org/10.1016/j.jhep.2012.01.004

14. Stigliano R, Marelli L, Yu D, et al. Seeding following percutaneous diagnostic and therapeutic approaches for hepatocellular carcinoma. What is the risk and the outcome? Seeding risk for percutaneous approach of HCC. Cancer Treat Rev 2007;33:437-447. http://dx.doi.org/10.1016/j.ctrv.2007.04.001

15. Demir OI, Obuz F, Sağol O, Dicle O. Contribution of diffusionweighted MRI to the differential diagnosis of hepatic masses. Diagn Interv Radiol 2007;13:81-86.

16. Kelekis NL, Semelka RC, Worawattanakul S, et al. Hepatocellular carcinoma in North America: a multi-institutional study of appearance on T1-weighted, T2-weighted, and serial gadolinium-enhanced gradient-echo images. AJR Am J Roentgenol 1998;170:1005-1013. http://dx.doi.org/10.2214/ajr.170.4.9530051

17. Hecht EM, Holland AE, Israel GM, et al. Hepatocellular carcinoma in the cirrhotic liver: gadolinium-enhanced 3D T1weighted MR imaging as a stand-alone sequence for diagnosis. Radiology 2006; 239: 438-447. http://dx.doi.org/10.1148/radiol.2392050551

18. Nasu K, Kuroki Y, Tsukamoto T, et al. Diffusion-weighted imaging of surgically resected hepatocellular carcinoma: imaging characteristics and relationship among signal intensity, apparent diffusion coefficient, and histopathologic grade. AJR Am J Roentgenol 2009;193:438-444. http://dx.doi.org/10.2214/AJR.08.1424

19. Xu PJ, Yan FH, Wang JH, et al. Contribution of diffusionweighted magnetic resonance imaging in the characterization of hepatocellular carcinomas and dysplastic nodules in cirrhotic liver. J Comput Assist Tomogr 2010;34:506-512. http://dx.doi.org/10.1097/RCT.0b013e3181da3671

20. Muhi A, Ichikawa T, Motosugi $U$, et al. High b-value diffusionweighted MR imaging of hepatocellular lesions: estimation of grade of malignancy of hepatocellular carcinoma. J Magn Reson Imaging 2009;30:1005-1011. http://dx.doi.org/10.1002/jmri.21931

21. Padhani AR, Liu G, Koh DM, et al. Diffusion-weighted magnetic resonance imaging as a cancer biomarker: consensus and recommendations. Neoplasia 2009;11:102-125. http://dx.doi.org/10.1593/neo.81328

22. Ichikawa T, Haradome H, Hachiya J, et al. Diffusion-weighted MR imaging with single-shot echo-planar imaging in the upper abdomen: preliminary clinical experience in 61 patients. Abdom Imaging 1999;24:456-461. http://dx.doi.org/10.1007/s002619900539

23. Ross BD, Moffat BA, Lawrence TS, et al. Evaluation of cancer therapy using diffusion magnetic resonance imaging. Mol Cancer Ther 2003;2:581-587. 